\title{
Effects of midwife-led maternity services on postpartum wellbeing and clinical outcomes in primiparous women under China's one-child policy
}

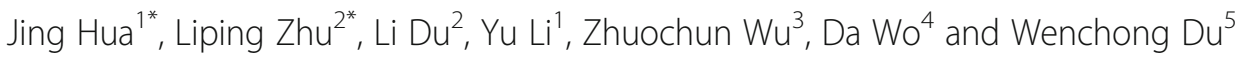

\begin{abstract}
Background: The Midwife-led maternity services have been implemented in China in response to the high rates of primiparous women and Caesarean Sections (CS) which may be related to China's one-child policy. However, few studies in China have been reported on the effectiveness of Midwife-led Care at Delivery (MCD) and the Continuity of Midwife-led Care (CMC) on postpartum wellbeing and other clinical outcomes. Therefore, evidence-based clinical validation is needed to develop an optimal maternity service for childbearing women in China.
\end{abstract}

Methods: A concurrent cohort study design was conducted with 1730 pregnant women recruited from 9 hospitals in Shanghai. Among the 1730 participants at baseline, 1568 participants completed the follow-up questionnaire, with a follow-up rate of $90.6 \%$.

Results: Compared with the routine Obstetrician-led Maternity Care (OMC), Midwife-led Care at Delivery (MCD) was associated with CS rate (OR were $0.16 ; 95 \% \mathrm{Cl}: 0.11$ to 0.25 ) and a higher total score of postpartum wellbeing ( $\beta$ were 2.70; $95 \% \mathrm{Cl}: 0.70$ to 4.70 ) when adjusting for the baseline differences and other confounders during delivery or postpartum period. Moreover, continuity of Midwife-led Care (CMC) was associated with CS rate (OR were 0.30; 95\%Cl: 0.23 to 0.41), as well as increased rate of breastfeeding within the first $24 \mathrm{~h}$ (OR were 2.49; 95\% Cl: 1.47 to 4.23), higher postpartum satisfaction ( $\beta=4.52 ; 95 \% \mathrm{Cl}$ : 1.60 to 12.68 ), lower anxiety ( $\beta$ were $0.66 ; 95 \% \mathrm{Cl}$ : 0.16 to 1.17), increased self-control ( $\beta$ were 0.39; 95\% Cl: 0.02 to 0.76 ) and a higher total score of postpartum wellbeing ( $\beta$ were 3.14; $95 \% \mathrm{Cl}: 1.54$ to 4.75$)$.

Conclusion: CMC is the optimal service for low-risk primiparous women under China's one-child policy, and is worthwhile for a general implementation across China.

Keywords: Midwife-led maternity services, Postpartum wellbeing, China's one-child policy

\section{Background}

There are many different models of maternity care available for looking after the health and wellbeing of pregnant women and newborns during pregnancy, labour and postpartum, each with their own distinct features based on local, cultural or social traditions and knowledge. Usually the obstetrician is the lead healthcare professional, but

\footnotetext{
* Correspondence: szhuaj@hotmail.com; shzhuliping@163.com

'Shanghai First Maternity and Infant Hospital, Tongji University School of Medicine, P.O. 2699 Gaoke Road, Shanghai 200042, China

${ }^{2}$ Shanghai Maternity and Child Health Care Center, P.O. 339 Gaoke Road,

Shanghai 200042, China

Full list of author information is available at the end of the article
}

other times a midwife might be in charge. This responsibility can also be shared between obstetricians and midwives, while in other instances the midwife is only involved during labour (Midwife-led Care at Delivery, MCD). One of the recent models is called the Continuity of Midwife-led Care (CMC), where the midwife is responsible for the health care of pregnant women from the initial booking appointment, through labour and all the way to postpartum.

Research have indicated that midwife-led models of care are associated with improved benefits for mothers and newborns, including shorter labour, and decreased

(c) The Author(s). 2018 Open Access This article is distributed under the terms of the Creative Commons Attribution 4.0 International License (http://creativecommons.org/licenses/by/4.0/), which permits unrestricted use, distribution, and reproduction in any medium, provided you give appropriate credit to the original author(s) and the source, provide a link to the Creative Commons license, and indicate if changes were made. The Creative Commons Public Domain Dedication waiver (http://creativecommons.org/publicdomain/zero/1.0/) applies to the data made available in this article, unless otherwise stated. 
likelihood to require intrapartum analgesia or report dissatisfaction with their childbirth experiences [1-3], which are typical indicators of optimal maternity care for low-risk childbearing women [4]. Midwife-led care facilitates birth, provides a better memory of the experience for the mothers, reduces or eliminates the need for medical intervention [5], decreases the number of maternal requested Caesarean Sections (CS) [6-8] and helps pregnant women form a strong bond with their midwives. Midwife-led care may also lead to improved maternal psychosocial outcomes [9-11], whereby pregnant women reported a stronger sense of emotional support, reassurance and were more in control during the midwives' antenatal care [12]. Midwives who offer continuity of care can also provide better support, information and guidance for the feeding of newborns $[3,4,13,14]$.

China's one-child family policy was introduced in 1979, restricting couples in urban areas to have only one child. Under the policy, most Chinese women are primiparous, and hence lack the experience of pregnancy and postpartum period. Moreover, the parents or parents-in-law of childbearing women are culturally expected to take the responsibility of caring for the new mothers and newborns from pregnancy to postpartum period. However, they may also lack the relevant experience because they have had only one child themselves under the population control policy and therefore may only be able to provide very limited assistance. Notably, due to the implementation of China's one-child policy [15], there has been a dramatic increase in the overall rate of CS $(54.90 \%$ throughout mainland China) over the past ten years [16, 17], and the most common reported indication for CS $(28.43 \%)$ was maternal request for none-medical reasons [18]. Therefore, a midwife who can provide consultation, birth planning (encouraging low-risk pregnant women to choice vaginal birth if their health conditions are permissible), parent education and psychological support to inexperienced primiparous pregnant women from childbirth through to postpartum period, can play an important role for primiparous women under the one-child policy [19].

However, current maternity services in China are predominantly hospital-based, with the obstetrician as the lead professional in routine antenatal checkup [20]. Recently, some Chinese hospitals have started to introduce the midwife-led care model [21-23], which generally provides one-to-one midwife-led care at delivery. A small proportion hospitals provides intentional continuity of midwife-led care from pregnancy to postpartum period $[17,24]$ Researchers have conducted pilot studies and reported that compared to the obstetrician-led antenatal care, midwife-led care is an effective way to reduce CS rate for childbearing women in mainland China [20]. Recently, an intervention study conducted in China showed that the midwife-led continuity care model decreased the CS rate and improved women's general satisfaction [17] compared with obstetrician-led antenatal care. To our knowledge, few studies with clinical validation have reported on the effectiveness of Midwife-led Care at Delivery (MCD) and the Continuity of Midwife-led Care (CMC), which is needed in order to develop an optimal maternity service for childbearing women under China's one-child policy. We therefore conducted a concurrent cohort study on maternal psychological outcomes in Shanghai, China. We hypothesized that midwife-led maternity care is an effective way to improving maternal satisfaction and wellbeing (i.e. general health, self-control, and vitality), reducing CS rates, and increasing the rate of breastfeeding. The continuity of midwife maternity care may be an optimal service for women due to their inexperience of maternity care under China's one-child policy. The aim of this study was: (1) to explore the effects of MCD and CMC on the delivery mode and rate of breastfeeding within the first $24 \mathrm{~h}$ in primiparous women when compared with Obstetrician-led Maternity Care (OMC) under China's one-child policy; (2) to compare the effectiveness of MCD and CMC with routine maternity care on postpartum satisfaction and wellbeing so as to provide the evidence for selecting an optimal maternity service in China.

\section{Methods \\ Participants}

A concurrent cohort study design (a follow-up study that compares outcomes between participants who have received an intervention and those who have not) was used to collect data at two time points (baseline and follow-up). In order to provide a better representation of sample data in this study, we randomly selected 8 hospitals from 8 separate districts across Shanghai. Throughout May 2013, Chinese childbearing women who attended the antenatal clinics of the 8 selected hospitals were eligible for the trial if they met the following inclusion criteria: (1) singleton pregnancy; (2) primiparous; (3) 29-30 weeks of gestation at recruitment; (4) absence of medical or obstetric complications. The exclusion criteria were: (1) fetal malformations; (2) severe personal, family-based psychiatric or medical history; (3) unable to provide consent. A total of 1902 childbearing women who were eligible based on the inclusion criteria were invited to take part in the study at baseline; 29 women were unable to provide the informed consent or refused to complete the questionnaire. A total of 1730 childbearing women were included in the cohort study, and finally 1568 women who completed the follow-up questionnaire with no missing information and had no fetal malformation were included in the final analysis (Fig. 1). 


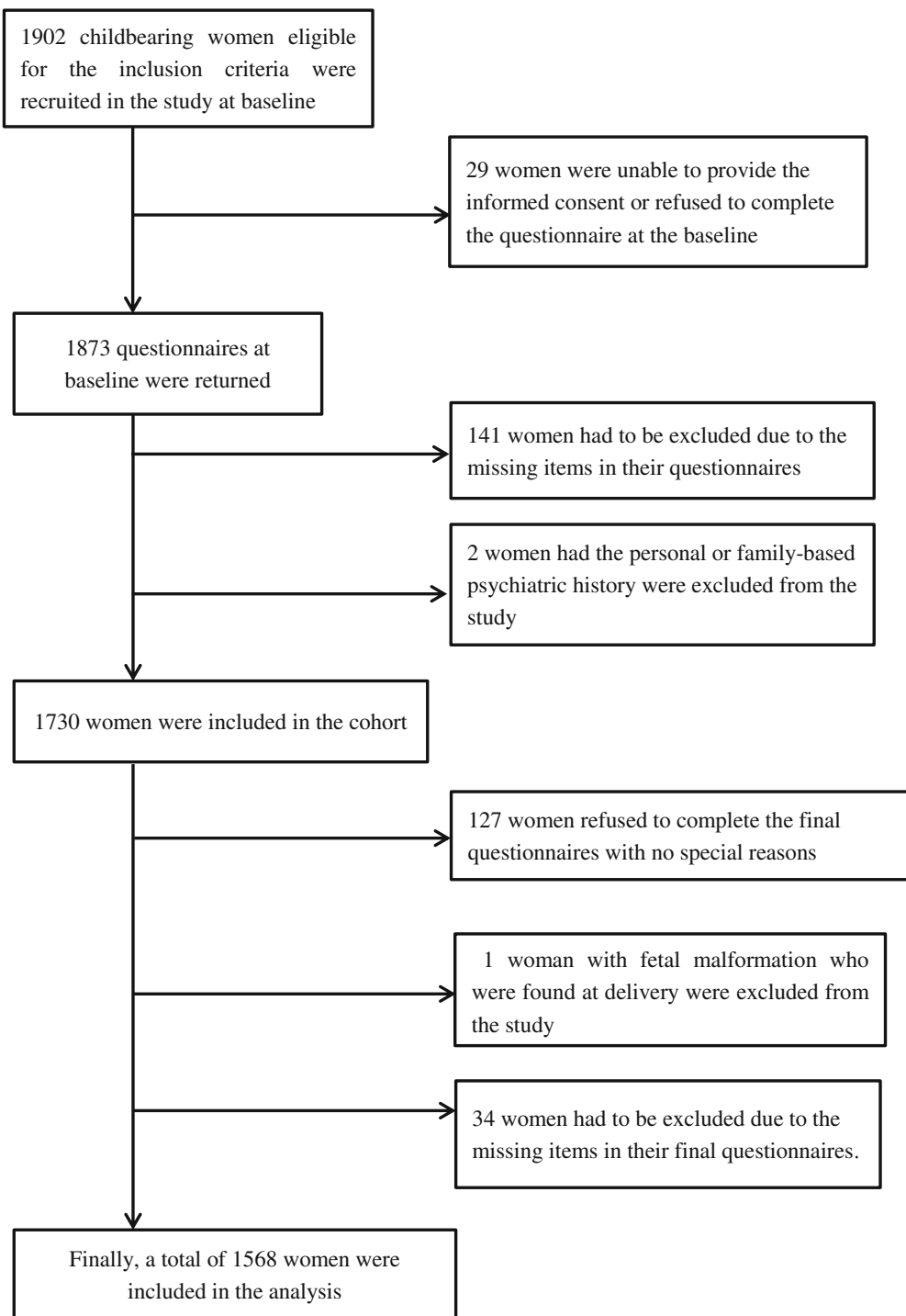

Fig. 1 Number of women who completed the baseline and follow-up investigations

\section{Measurements}

The General Wellbeing Schedule (GWBS) was used to assess maternal wellbeing at baseline and follow-up. GWBS is an 18-item multi-dimensional scale developed by Dr. Harold Deputy and revised by Frazio [25]. It covers six dimensions of subjective feelings of psychological wellbeing: without anxiety (the 10th and 15th items), without depression (the 4th, 12th, and 18th items), general health (the 2nd, 5th, 8th, 16th items), positive wellbeing (the 6th and 11 th items), self-control (the 3rd, 7th, 13th items), and vitality (1st, 9th, 14th, and 17th items). The GWBS scale has been translated into Chinese and have since been validated in China [26]; the internal consistency (Cronbach's alpha coefficients of male and female were 0.91 and 0.95 respectively) and construct validity (Pearson correlation coefficients between the scores of each item and total score were from 0.65 to 0.88 ) of GWBS in Chinese have been reported to be reliable. A higher score reflected the increased maternal wellbeing.

A self-reported questionnaire was developed to measure women's demographic and clinical characteristics at baseline [27]. The satisfaction with childbirth experiences in prenatal and perinatal care was assessed using a self-reported follow-up questionnaire. The follow-up questionnaire also inquired about the women's mode of delivery, time of gestation at delivery, whether breastfeeding was commenced within $24 \mathrm{~h}$, and presence of newborn malformations [27].

\section{Model of maternity service}

In OMC model, obstetricians are the primary providers of maternal care to pregnant women. However, because 
pregnant women are required to visit the obstetrician's antenatal clinic at the out-patient department, it is likely that they would have met a different obstetrician on each visit. Furthermore, when the pregnant women came into the hospital for labour, they would also be cared for by an obstetrician who was rostered for duty on that day.

In the CMC model, the midwives (usually undertaken by nurses who hold certification from the local health bureau and have received specific post-nursing training in midwifery for 1 to 3 years, as well as passed the qualification test) provide assistance to healthy women with low-risk pregnancies. Thus, a small group of midwives are usually responsible for providing care to the pregnant women including antenatal checkups, consultation, birth planning, parenting education. They are also responsible for providing care during labour, birth and the immediate postpartum period, and collaborating with obstetricians and other health professionals. The advantages of this midwife-led plan include providing continuous emotional support to the pregnant women, thereby minimizing intra-partum fetal monitoring, offering alternatives to pain relief (pharmacological or non-pharmacological), providing different positions that allow free movement, reduction of episiotomy, and promoting mother and child bonding such as facilitating skin-to-skin contact between mother and baby, as well as encouraging breastfeeding after birth. However, childbearing women also have the right to select the other model (MCD) at their own discretion. In the MCD model, the pregnant woman would visit the obstetrician for consultation during pregnancy, and thereafter receive one-to-one care by a designated midwife from the onset of labour to $2 \mathrm{~h}$ postpartum.

\section{Procedure}

The survey was conducted from May to October 2010. The questionnaire at baseline was filled out by the pregnant women when they attended regular health education courses conducted by hospitals. We conducted the follow-up investigation on day 7 postpartum. Women were asked to fill out the questionnaire according to the instructions given by the researchers of the study.

\section{Statistical analysis}

Data were analyzed using the SPSS 17.0 program. Independent-samples $t$ tests and Chi-square tests performed to compare the 2 groups at the baseline. Multiple linear regression analyses were used to assess the effects of MCD and CMC on delivery mode and maternal satisfaction, after adjusting for hospitals, baseline differences and the other confounders during birth. All variables were simultaneously included in the model. Because the Variance Inflation Factor (VIF) of each predictor in the model was less than 10 , the multicolinearity was not statistically significant. Therefore, the colinearity was not considered in the model. Multiple logistic regression models were used to analyze the effects of MCD and $\mathrm{CMC}$ on maternal wellbeing after adjusting for hospitals, baseline differences and other confounders during birth. A value of 0.05 was used for all tests of significance.

\section{Results}

\section{Baseline}

Of the 1730 participants at baseline, 1568 participants completed the follow-up questionnaire (Fig. 1), with a follow-up rate of $90.6 \%$. All women were allowed to choose their preferred type of care $(\mathrm{MCD}, \mathrm{CMC}$ or OMC). Among these participants, 279 (17.8\%) women selected the MCD, 172 (10.1\%) women selected the CMC, and 1117 (71.1\%) selected the routine obstetrician-led care birth. Table 1 shows the distribution of selected characteristics among participants who chose the different birth-care services. At cohort entry, the proportions of maternal age, and multiple gestation was equal (each $P>0.05$; Table 1), whereas the proportions of ethnicity, education, occupation, and method of payment were not equal (each $P<0.05$; Table 1 ). However, the degree of maternal wellbeing (non-anxiety, non-depression, positive wellbeing and self-control) in the two birth-care services were significantly different with the routine $\mathrm{OMC}$ group (each $P<0.05$; Table 2).

\section{Delivery mode}

Table 2 shows the associations of MCD and CMC with the delivery mode and rate of breastfeeding in the first $24 \mathrm{~h}$. We found that odds of caesarean section when compared with OMC were decreased significantly with CMC (OR 0.30; 95\% CI: 0.22 to 0.40) and with MCD (OR 0.17; $95 \%$ CI: 0.11 to 0.25 ). The rates of caesarean section in CMC (OR 0.30; 95\%CI: 0.23 to 0.41) and MCD (OR 0.16; 95\%CI: 0.11 to 0.25 ) group also decreased when adjusting for baseline differences and other confounders at delivery or postpartum period (Table 3).

\section{Breastfeeding}

The rate of breastfeeding in the first $24 \mathrm{~h}$ was only increased in the CMC group when the baseline differences and other confounders at delivery or postpartum period were adjusted for (OR 2.49; 95\% CI:1.47, 4.23) or not adjusting for (OR 2.46; 95\% CI: 1.46,4.13) (Table 3).

\section{Satisfaction}

In our study, the satisfaction level increased only in the CMC group when the baseline differences and other confounders at delivery or postpartum period were adjusted for (OR 4.58; 95\% CI: 1.63 to 12.86) or not adjusted for (OR 4.52; 95\% CI: 1.60 to 12.68 ). 
Table 1 Demographic and clinical characteristic of participants at baseline

\begin{tabular}{|c|c|c|c|c|c|}
\hline Characteristic & Total $n=1568$ & OMC $^{\mathrm{a}}$ group $n=1117$ & $M_{C D}{ }^{b}$ group $n=279$ & $\mathrm{CMC}^{\mathrm{C}}$ group $n=172$ & $P$ \\
\hline$\overline{\text { Maternal age }[M(S D)]^{d}}$ & $28.52(3.59)$ & $28.47(3.74)$ & $28.12(3.33)$ & $29.53(2.77)$ & $<0.001^{* * *}$ \\
\hline \multicolumn{6}{|l|}{ Ethnicity $n(\%)^{\mathrm{e}}$} \\
\hline Han & $1503(95.9)$ & $1069(95.7)$ & $266(95.3)$ & $168(97.7)$ & \multirow[t]{2}{*}{0.431} \\
\hline Non-Han & $65(4.1)$ & $48(4.3)$ & $13(4.7)$ & $4(2.3)$ & \\
\hline \multicolumn{6}{|l|}{ Education $n(\%)^{\mathrm{e}}$} \\
\hline College or university & $1173(74.8)$ & $832(74.5)$ & $176(63.1)$ & $16,595.9$ & \multirow[t]{3}{*}{$<0.001^{* * *}$} \\
\hline Middle school & $303(19.4)$ & $224(20.1)$ & $73(26.2)$ & $6(3.9)$ & \\
\hline Primary school or below & $92(5.8)$ & $61(5.5)$ & $30(10.8)$ & $1(0.2)$ & \\
\hline \multicolumn{6}{|l|}{ Vacation $n(\%)^{\mathrm{e}}$} \\
\hline Company employee & $338(21.6)$ & $233(20.9)$ & $82(29.4)$ & $23(13.4)$ & \multirow[t]{5}{*}{$<0.001^{* * *}$} \\
\hline Private owner & $108(6.9)$ & $87(7.8)$ & $12(4.3)$ & $9(5.2)$ & \\
\hline Technician and liberal profession & $642(40.9)$ & $449(40.2)$ & $96(34.4)$ & $97(56.4)$ & \\
\hline Unemployed & $291(18.6)$ & $210(18.8)$ & $61(21.9)$ & $20(11.6)$ & \\
\hline Others & $189(12.1)$ & $138(12.4)$ & $28(10.0)$ & $23(13.4)$ & \\
\hline \multicolumn{6}{|l|}{ Multiple Gestation $n(\%)^{\mathrm{e}}$} \\
\hline No & $1171(74.7)$ & $855(76.5)$ & $194(69.5)$ & $122(72.6)$ & \multirow[t]{2}{*}{0.055} \\
\hline Yes & $397(25.3)$ & $266(23.5)$ & $85(30.5)$ & $46(27.4)$ & \\
\hline \multicolumn{6}{|l|}{ Method of payment $n(\%)^{\mathrm{e}}$} \\
\hline Self-payment & $512(32.7)$ & $368(32.9)$ & $120(43.0)$ & $24(14.0)$ & \multirow[t]{3}{*}{$0.001^{* *}$} \\
\hline Government insurance & $707(45.1)$ & $501(44.9)$ & $105(37.6)$ & $101(58.7)$ & \\
\hline Private insurance & $349(22.3)$ & $248(22.2)$ & $54(19.4)$ & $47(27.3)$ & \\
\hline
\end{tabular}

${ }^{a}$ Obstetrician-led Maternity Care

bMidwife-led Care at Delivery

${ }^{c}$ Continuity of Midwife-led Care

dOne-way ANOVA

'Pearson's chi-squared test

${ }^{*} p<0.05,{ }^{* *} p<0.01,{ }^{* * *} p<0.001$

\section{Maternal wellbeing}

We conducted the follow-up investigation at day 7 postpartum. The total score of postpartum wellbeing increased with MCD ( $\beta 2.41 ; 95 \%$ CI:0.83 to 3.96) and CMC ( $\beta 3.11$; 95\% CI:1.18 to 5.04) when confounders were not considered. The total score of wellbeing also increased with
$\operatorname{MCD}(\beta 2.70 ; 95 \%$ CI:0.70 to 4.70$)$ and CMC ( $\beta 3.14 ; 95 \%$ CI:1.54 to 4.75) after adjusting for the baseline differences and other confounders at delivery or postpartum period. The score of "anxiety" (a higher score indicating lower anxiety) was higher in CMC group when the baseline differences and other confounders were adjusted for

Table 2 Maternal wellbeing of participants at baseline

\begin{tabular}{|c|c|c|c|c|c|}
\hline Characteristic & Total $n=1568$ & OMC $^{\mathrm{a}}$ group $n=1117$ & $\mathrm{MCD}^{\mathrm{b}}$ group $n=279$ & $\mathrm{CMC}^{\mathrm{C}}$ group $n=172$ & $P$ \\
\hline \multicolumn{6}{|c|}{ Maternal wellbeing $[\mathrm{M}(\mathrm{SD})]^{\mathrm{d}}$} \\
\hline Anxiety & $7.72(2.32)$ & $7.63(2.50)$ & $8.01(2.53)$ & $7.85(2.30)$ & $<0.001^{* * *}$ \\
\hline Depression & $16.12(6.35)$ & $16.39(6.05)$ & $13.65(8.16)$ & $18.41(6.44)$ & $<0.001^{* * *}$ \\
\hline General health & $19.04(4.67)$ & $19.11(4.63)$ & $17.72(5.10)$ & $20.77(4.51)$ & $<0.001^{* * *}$ \\
\hline Positive wellbeing & $17.12(2.37)$ & $17.05(2.31)$ & $17.65(2.86)$ & $16.77(2.63)$ & $<0.001^{* * *}$ \\
\hline Self-control & $27.28(2.72)$ & $27.16(2.66)$ & $27.98(3.29)$ & $26.94(2.67)$ & $<0.001^{* * *}$ \\
\hline Vitality & $28.07(4.02)$ & $28.13(3.96)$ & $26.86(4.33)$ & $29.63(3.98)$ & $<0.001^{* * *}$ \\
\hline Total score & $115.36(11.86)$ & 115.48 (11.85) & $112.12(12.37)$ & 119.85(10.33) & $<0.001^{* * *}$ \\
\hline
\end{tabular}

${ }^{\mathrm{a} O b s t e t r i c i a n-l e d ~ M a t e r n i t y ~ C a r e ~}$

${ }^{\mathrm{b}}$ Midwife-led Care at Delivery

${ }^{c}$ Continuity of Midwife-led Care

dOne-way ANOVA

${ }^{*} p<0.05,{ }^{* *} p<0.01,{ }^{* * *} p<0.001$ 
Table 3 Effects of MCD and CMC on delivery mode and rate of breastfeeding in $24 \mathrm{~h}$

\begin{tabular}{|c|c|c|c|c|c|c|c|}
\hline \multirow[t]{2}{*}{ Outcome variables } & \multirow{2}{*}{$\begin{array}{l}\text { OMC }^{a} \text { group } \\
\text { (\%) } n=1117\end{array}$} & \multirow{2}{*}{$\begin{array}{l}\mathrm{MCD}^{\mathrm{b}} \text { group } \\
(\%) n=279\end{array}$} & \multirow{2}{*}{$\begin{array}{l}\text { CMC }^{\mathrm{C}} \text { group } \\
(\%) n=172\end{array}$} & \multicolumn{2}{|l|}{ MCD vs. OMC } & \multicolumn{2}{|l|}{ CMC vs. OMC } \\
\hline & & & & $\mathrm{COR}^{\mathrm{d}}(95 \% \mathrm{Cl})$ & $\mathrm{aOR}(95 \% \mathrm{Cl})$ & $\mathrm{COR}^{\mathrm{d}}(95 \% \mathrm{Cl})$ & $\mathrm{aOR}^{\mathrm{e}}(95 \% \mathrm{Cl})$ \\
\hline \multicolumn{8}{|l|}{ Delivery mode $\mathrm{n}(\%)$} \\
\hline Vaginal birth & $461(41.3)$ & $139(80.8)$ & 196 (70.3) & Ref & Ref & Ref & $\operatorname{Ref}^{e}$ \\
\hline Caesarean section & $656(58.7)$ & $33(19.2)$ & $83(29.7)$ & $0.17(0.11,0.25)^{* * *}$ & $0.16(0.11,0.25)^{e * * *}$ & $0.30(0.22,0.40)^{* * *}$ & $0.30(0.23,0.41)^{e_{* * *}}$ \\
\hline \multicolumn{8}{|c|}{ Breastfeeding in first $24 \mathrm{~h} \mathrm{n}(\%)$} \\
\hline No & $1006(90.1)$ & $233(83.5)$ & $136(78.8)$ & Ref & Ref & Ref & $\operatorname{Ref}^{f}$ \\
\hline Yes & $111(9.90)$ & $46(16.5)$ & $36(21.2)$ & $1.36(0.96,1.93)$ & $1.38(0.97,1.96)^{f}$ & $2.46(1.46,4.13)^{* *}$ & $2.49(1.47,4.23)^{f * *}$ \\
\hline \multicolumn{8}{|c|}{ 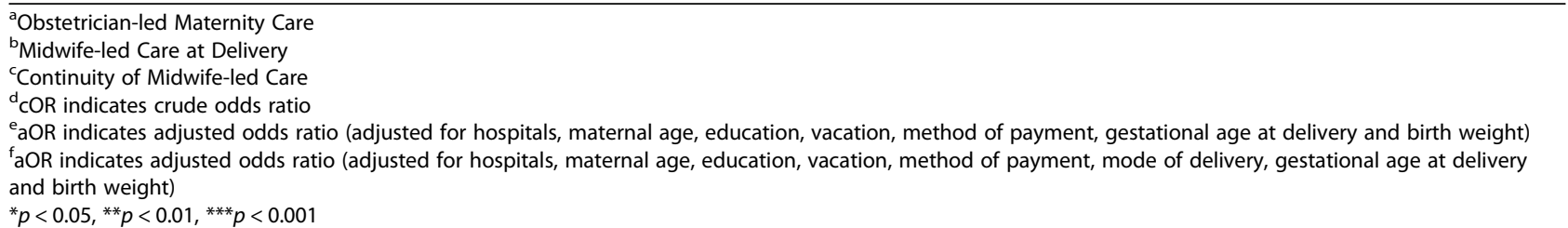 } \\
\hline
\end{tabular}

( $\beta 0.66$; 95\% CI:0.16 to 1.17$)$ or not adjusted for ( $\beta 0.81$; $95 \%$ CI:0.33 to 1.29). The score of "self-control" was also increased in CMC group when the baseline differences and other confounders were adjusted for $(\beta 0.39$; $95 \%$ CI:0.02 to 0.76$)$ or not adjusted for $(\beta 0.38 ; 95 \%$ CI:0.03 to 0.72) (Table 4).

\section{Discussion}

The principles of the midwife-led service were to provide a home-like environment, minimize intervention, facilitate normal birth, improve women's birth experiences and enhance the role of midwives. The present study provided supportive clinical evidence on the effectiveness of the midwife-led maternity services for inexperienced primiparous women under China's one-child policy. Other than increased vaginal birth and breastfeeding rates, the continuity of midwife-led service has contributed to improving the maternal wellbeing and satisfaction in low-risk primiparous women with limited experience under China's one-child policy.

This study demonstrated that low-risk primiparous women who received the $\mathrm{CMC}$ or $\mathrm{MCD}$ services were less likely to undergo caesarean section than those who received the standard obstetrician-led birth care. These results supported previous studies that showed continuity of midwife-led care with a focus on normal birth in a friendly supportive birth environment makes a significant difference on the mode of delivery $[4,10,19,23]$ For low-risk pregnant women, collaboration and support other than standard obstetric management allowed a greater number of spontaneous vaginal deliveries [28]. It has been reported that midwives could provide plenty of information regarding childbirth to childbearing women. Increased self-confidence brought about by the presence

Table 4 Effects of MCD and CMC on women's postpartum wellbeing

\begin{tabular}{|c|c|c|c|c|c|c|c|}
\hline \multirow[t]{2}{*}{ Outcome variables } & \multirow{2}{*}{$\begin{array}{l}\mathrm{OMC}^{\mathrm{a}} \text { group } \\
n=1117 \mathrm{M}(\mathrm{SD})\end{array}$} & \multirow{2}{*}{$\begin{array}{l}\text { MCD }^{b} \text { group } \\
n=451 \mathrm{M}(\mathrm{SD})\end{array}$} & \multirow{2}{*}{$\begin{array}{l}\mathrm{CMC}^{\mathrm{C}} \text { group } \\
n=172 \mathrm{M}(\mathrm{SD})\end{array}$} & \multicolumn{2}{|l|}{ MCD vs. OMC } & \multicolumn{2}{|l|}{ CMC vs. OMC } \\
\hline & & & & $\overline{\beta^{d}}(95 \% C l)$ & $\beta^{e}(95 \% C l)$ & $\overline{\beta^{d}}(95 \% C l)$ & $\beta^{e}(95 \% C l)$ \\
\hline $\begin{array}{l}\text { Anxiety(the higher } \\
\text { score the less anxiety) }\end{array}$ & $7.77(4.26)$ & $8.14(3.03)$ & $8.28(2.75)$ & $0.14(-0.25,0.54)$ & $0.07(-0.34,0.47)$ & $0.81(0.33,1.29)^{* *}$ & $0.66(0.16,1.17) *$ \\
\hline $\begin{array}{l}\text { Depression(the higher } \\
\text { score the less } \\
\text { depression) }\end{array}$ & $18.79(2.88)$ & $18.83(2.74)$ & $18.95(2.85)$ & $0.04(-0.34,0.41)$ & $0.20(-0.18,0.59)$ & $0.16(-0.29,0.62)$ & $0.19(-0.29,0.67)$ \\
\hline General health & $21.55(3.70)$ & $21.18(4.05)$ & $21.39(3.87)$ & $-0.38(-0.88,0.12)$ & $-0.12(-0.62,0.39)$ & $-0.17(-0.77,0.44)$ & $-0.16(-0.80,0.50)$ \\
\hline Positive wellbeing & $16.97(1.74)$ & $16.82(1.88)$ & $17.23(1.73)$ & $-0.15(-0.38,0.08)$ & $-0.12(-0.36,0.12)$ & $0.25(-0.03,0.54)$ & $0.27(-0.03,0.57)$ \\
\hline Self-control & $26.95(2.11)$ & $26.80(2.51)$ & $27.33(1.95)$ & $-0.15(-0.43,0.14)$ & $-0.16(-0.45,0.14)$ & $0.38(0.03,0.72)^{*}$ & $0.39(0.02,0.76)^{*}$ \\
\hline Vitality & $29.89(3.46)$ & $29.73(3.56)$ & $29.99(3.15)$ & $-0.17(-0.62,0.28)$ & $0.01(-0.45,0.47)$ & $0.09(-0.47,0.64)$ & $-0.03(-0.61,0.55)$ \\
\hline Total score & $122.89(11.94)$ & $125.30(11.99)$ & $126.10(12.48)$ & $2.41(0.83,3.96)^{*}$ & $2.70(0.70,4.70)^{*}$ & $3.11(1.18,5.04) * * *$ & $3.14(1.54,4.75)^{* * *}$ \\
\hline
\end{tabular}

${ }^{a}$ Obstetrician-led Maternity Care

${ }^{\mathrm{b}}$ Midwife-led Care at Delivery

${ }^{c}$ Continuity of Midwife-led Care

${ }^{\mathrm{d}} \mathrm{COR}$ indicates crude odds ratio

eaOR indicates adjusted odds ratio (adjusted for hospitals, maternal age, education, vacation, method of payment, mode of birth, gestational age at delivery and birth weight)

${ }^{*} p<0.05,{ }^{* *} p<0.01,{ }^{* * *} p<0.001$ 
of midwives made childbearing women more confident in facing labour [29]. However, in most areas in China, obstetrician-led birth care remains the most common form of pregnancy healthcare management. This physician-based obstetric care model is more likely to turn birth from natural process to a contrived medical process. A pregnant woman is often considered as a patient, and is therefore more likely to receive frequent obstetric intervention [30]. Under these circumstances, normal child birth usually ends up as caesarean delivery.

Breastfeeding education from midwives also plays an important role in protecting and supporting breastfeeding women [31, 32]. In our study, the continuity of midwife-led maternity service has been found to be linked to an increased rate of breastfeeding for inexperienced primiparous woman. However, the MCD service did not improve the breastfeeding rate. Breastfeeding knowledge from health professionals involves providing supportive attitudes and behaviors, but this knowledge must be accurate and thorough to effectively promote breastfeeding [33]. Multiple studies have shown that inconsistent and conflicting advices are detrimental to breastfeeding outcomes [34-36]. In the MCD model, the childbearing women may receive inconsistent information about breastfeeding during pregnancy because it is likely that they would have met a different obstetrician on each visit to the antenatal clinic at the out-patient department. Furthermore, they may also receive limited information regarding breastfeeding because the midwives in MCD care condition only provide services from labour to $2 \mathrm{~h}$ postpartum.

We observed that the continuity of midwife-led service was associated with increased women's satisfaction. Similar to other studies on the continuity of midwifery care [37], women were more likely to feel satisfied with midwives in terms of information transfer, choices and decisions, and were more pleased with the antenatal and intra-partum care provided by the midwives compared to other models [38]. A recent review reported that women who received midwife-led continuity models of care were less likely to experience intervention and more likely to be satisfied with their maternity care compared to women who received other models of care [26]. The results of the current study were also consistent with a previous report that showed low-risk pregnant women in China were more likely to be satisfied with the care and support of midwives [39]. Many studies have showed that women in labour are more appreciative of reliable midwifery practice [40], especially health professionals who are open to listening, being honest, and can provide both physical and emotional support; in other words, the professionals who showed ability to care for the women's needs during labour [41-44]. As previous studies have pointed out
[45], the psychosocial aspects of birth care, as well as information and caregiver support are the most important factors associated with antenatal satisfaction; whereas the lack of support from midwives or other inappropriate antenatal services are often linked to dissatisfaction. However, our study did not observe any association between MCD and women's satisfaction due to the limited service provided by the midwife from labour to $2 \mathrm{~h}$ postpartum.

In this study, we found that compared to the routine obstetrician-led birth care, the CMC service resulted in improved postpartum wellbeing, increased self-control and lower anxiety. However, MCD only had a positive influence on overall wellbeing. These results were similar to previous studies that showed midwife-led care could improve the maternal psychological status. Receiving support from midwives was one of the most effective methods to reduce the level of maternal anxiety [46]. Homer et al. also reported that women who had a familiar midwife during labour had a significantly higher sense of 'control' and a more positive childbirth experience compared to women with an unfamiliar midwife [10]. Cheung et al. [29] pointed out that there was a significant negative association between maternal anxiety and feelings of control during labour. Researchers [47] also reported that maternal feelings of control during labour might help in decreasing the level of anxiety during pregnancy.

\section{Strength and limitation}

We conducted the present study on low-risk primiparous women in order to avoid other possible confounders such as severe complications during pregnancy, which may influence the wellbeing of multiparous women. In addition, the majority of childbearing women were primiparous under the rigorous birth control policy in urban areas of Mainland China. Therefore, it is difficult to compare the effectiveness of midwife-led maternity services between women under the one-child policy and women who are caring for their second child. However, since the one-child policy in China has been relaxed since 2016, we may be able to compare the effectiveness of midwife-led care between women under both policies in the future. However, caution should be made for the generalization of our results to the general obstetric population. Selection bias may exist in our study, including 29 women who refused to take part in our study at baseline, and 162 women with missing data or were excluded from the follow-up investigation. Moreover, women with a higher level of psychological well-being during the pregnancy are more likely to take part in our study and completing the follow-up investigation, which may affect the generalization of the study. A randomized intervention study may be necessary in the near future. 


\section{Conclusions}

Using a concurrent cohort study design, we found that the introduction of CMC significantly improved vaginal birth rate, breastfeeding rate, maternal satisfaction and overall wellbeing in pregnant women. However, MCD was only associated with vaginal mode of delivery and overall wellbeing. This study provides supportive evidence that $\mathrm{CMC}$ is the optimal healthcare service for the management of low-risk primiparous women under China's one-child policy. Therefore a general implementation of CMC in Shanghai and across China should be encouraged. In our study, the majority of women (71.1\%) still received the routine obstetrician-led birth care. Further efforts should be made to inform the public on the advantages of $\mathrm{CMC}$ in low-risk pregnant women.

\section{Abbreviations}

aOR: Adjusted odds ratio; Cl: Confidence interval; CMC: The continuity of midwife-led care; cOR: Crude odds ratio; CS: Caesarean sections; MCD: Midwife-led Care at Delivery; OMC: Obstetrician-led Maternity Care; VIF: Variance Inflation Factor

\section{Acknowledgements}

The authors wish to thank the researchers and investigators from the 8 hospitals who participated in the distribution and collection of the questionnaires. We also thank Maya Chopra for language editing.

\section{Funding}

This study was supported by National Natural Science Foundation of China under Grant(81673179, 81402687), the Shenkang Hospital Development Center under Grant(SHDC12016239,16CR1014A), the Fourth Round of Shanghai Three-year Action Plan on Public Health Discipline and Talent Program: Women and Children's Health under Grant (15GWZK0401),and Shanghai Municipal Commission of Health and Family Planning under Grant (201640060,2017ZZO2015).

\section{Availability of data and materials}

Data sets generated and/or analysed during the current study available from the corresponding author on reasonable request

\section{Authors' contributions}

$\mathrm{JH}$ and LZ contributed to design, execution, analysis and writing of the study. ZW was responsible for the study design and approval of the submitted version. DL, YL, DW, and WD contributed to acquisition of data and interpretation of data, and revising sections of the paper according to the reviewer's suggestions. All authors have read and approved the final version of the manuscript.

\section{Ethics approval and consent to participate}

Ethical clearance was obtained from the ethics committees of the Shanghai First Maternity and Infant Hospital (KS1658). The study was carried out in accordance with the approved guidelines. The purposes of the study were explained to all participants verbally. Participants were assured of the confidentiality and anonymity. All participants signed an informed consent form prior to enrolment in the study. The participants were advised that they could withdraw from the study at any time they wished.

\section{Consent for publication}

Not applicable.

\section{Competing interests}

The authors declare that they have no competing interests. The funding from National Natural Science Foundation of China under Grant $(81,673,179$, 81,402,687), the Shenkang Hospital Development Center under Grant(SHDC12016239,16CR1014A) play the roles in the study design and data collection. The study is also supported by the Fourth Round of Shanghai Three-year Action Plan on Public Health Discipline and Talent
Program: Women and Children's Health under Grant (15GWZK0401), Shanghai Municipal Commission of Health and Family Planning under Grant $(201,640,060,2017 Z Z 02015)$ for analysis and interpretation of data and in writing and revising the manuscript.

\section{Publisher's Note}

Springer Nature remains neutral with regard to jurisdictional claims in published maps and institutional affiliations.

\section{Author details}

${ }^{1}$ Shanghai First Maternity and Infant Hospital, Tongji University School of Medicine, P.O. 2699 Gaoke Road, Shanghai 200042, China. ${ }^{2}$ Shanghai Maternity and Child Health Care Center, P.O. 339 Gaoke Road, Shanghai 200042, China. ${ }^{3}$ Health Statistics and Social Medicine Department of Public health School, Fudan University, Shanghai 200002, China. ${ }^{4}$ Research Center for Translational Medicine, East Hospital, Tongji University School of Medicine, Shanghai 200002, China. ${ }^{5}$ Division of Psychology, Nottingham Trent University, Chaucer Building 4013, Burton Street, Nottingham NG1 4BU, UK.

Received: 1 January 2017 Accepted: 6 August 2018

Published online: 13 August 2018

References

1. Koblinsky M, Matthews Z, Hussein J, Lancet Maternal Survival Series steering group. Going to scale with professional skilled care. Lancet. 2006;368(9544): 1377-86.

2. Sandall J, Soltani H, Gates S, Shennan A, Devane D. Midwife-led versus other models of care for childbearing women. Cochrane Database Syst Rev. 2016; 28:4:CD004667. https://doi.org/10.1002/14651858.CD004667.

3. Blackman I, Sweet L, Byrne J. Using Rasch analysis to identify midwifery students' learning about providing breastfeeding support. Women Birth pii: S1871-5192. (15):00017-7. https://doi.org/10.1016/j.wombi.2015;02.001.

4. Hodnett ED. Continuity of Care Givers for Care During Pregnancy and Childbirth. The Cochrane Library.Update Software, 2001;Oxford Issue 3.

5. Pascali-Bonaro D, Kroeqer M. Continuous female companionship during childbirth: a crucial resource in times of stress or calm. J Midwifery Womens Health. 2004;49(4 Suppl 1):19-27.

6. Cooke HM, Waters DL, Dyer K, Picone D. Development of a best practice model of midwife-led antenatal care. Aust Midwifery. 2004;17:21-5.

7. Bick D. Enhancing safety in the maternity services: a greater role for midwife-led care? Midwifery. 2009;25:1-2.

8. Spiby H, Munro J. The development and peer review of evidence based guidelines to support midwifery led care in labour. Midwifery. 2009;25:3-171.

9. Harvey S, Jarrell J, Brant R, Staiton C, Rach DA. Randomized controlled trial of nurse-midwifery care. Birth. 1996:23:128-35.

10. Homer CS, Davis GK, Brodie PM, Chapman MG. Collaboration in maternity care: a randomised controlled trial comparing community based continuity of care with standard hospital care. BJOG. 2001;108:16-22.

11. Hodnett ED, Fredericks S, Weston J. Support during pregnancy for women at increased risk of low birthweight babies. Cochrane Database Syst Rev. 2010;16:CD000198.

12. Gu C, Wu X, Ding Y, Zhu X, Zhang Z. The effectiveness of a Chinese midwives' antenatal clinic service on childbirth outcomes for primipare: a randomised controlled trial. Int J Nurs Stud. 50(12):1689-97. https://doi.org/ 10.1016/j.jijnurstu.2013:05.001

13. Schmied V, Beake S, Sheehan A, McCourt C, Dykes F. A meta-synthesis of women's perceptions and experiences of breastfeeding support. JBI Libr of Syst Rev. 2009;7(14):583-614.

14. McCourt C, Stevens T. Relationship and Reciprocity in Caseload Midwifery. In: Deery $R$, Hunter B, editors. Emotions in midwifery and reproduction. Basingstoke, Hants: Palgrave Macmillan; 2008. And on support for breastfeeding

15. Ufang G, Padmadas SS, Fengmin Z, Brown JJ, Stones RW. Delivery settings and caesarean section rates in China. Bull World Health Organ. 2007;85(10): 755-62.

16. Tang S, Li X, Wu Z. Rising cesarean delivery rate in primiparous women in urban China: evidence from three nationwide household health surveys. Am J Obstet Gynecol. 2006;195(6):1527-32. 
17. Klemetti R, Che X, Gao Y, Raven J, Wu Z, Tang S, Hemminki E. Cesarean section delivery among primiparous women in rural China: an emerging epidemic. Am J Obstet Gynecol. 2010;202(1):65 e61-6.

18. Liu Y, Li G, Chen Y, Wang X, Ruan Y, Zou L, Zhang W. A descriptive analysis of the indications for caesarean section in mainland China. BMC Pregnancy Childbirth. 2014;12(14):410. https://doi.org/10.1186/s12884-014-0410-2.

19. Sandall J, Soltani H, Gates S, Shennan A, Devane D. Midwife-led continuity models versus other models of care for childbearing women. Cochrane Database Syst Rev. 2016;4:CD004667. https://doi.org/10.1002/14651858. CD004667.pub5.

20. Gu CY, Zhang Z, Ding Y. Chinese midwives' experience of providing continuity of care to labouring women. Midwifery. 2011;27:243-9.

21. Li C, Zhang L, Ye L, Yang Q, Zhang C, Wan Y (Eds.),. The Call of Life: a Strategic Action and Prospect for a Safe Motherhood Initiative. The Department of Public Health and the Maternity and Child Welfare of the State Public Health Ministry, The United Nations Children's Fund, 2003;The Women, Children Office of the State Council.

22. Mander R, Cheung NF. Issues arising in the planning of a cross-cultural research project in China. Clin Eff Nurs. 2006;9:212-20.

23. Cheung NF, Mander R, Wang $X$, Zhang L. Views of Chinese women and health professionals about midwife-led care in China. Midwifery. 2011:27:842-7.

24. Homer CS, Davis GK, Cooke M, Barclay LM. Women's experiences of continuity of midwifery care in a randomised controlled trial in Australia. Midwifery. 2002;18(2):102-12

25. Fazio AF. A concurrent validational study of the MCH general well-being schedule. Vital Health Statistics 2. 1977;(73):1-53.

26. Duan JH. The application of General Well-Being Schedule in university students. Chin J Clin Psych. 1996;4:56-7. In Chinese

27. Hua J, Zhu L, Wenchong D, Li D, Luo T, Zhuochun W. Infant's sex, birth control policy and postpartum well-being: a prospective cohort study in Shanghai, China. BMJ Open. 2016;6:e012207. https://doi.org/10.1136/ bmjopen-2016-012207.

28. Jackson DJ, Lang JM, Swartz WH, Nguyen U. Outcomes, safety, and resource utilization in a collaborative care birth center program compared with traditional physician-based perinatal care. Am J Public Health. 2003;93:999-1006.

29. Wang Z, Sun W, Zhou H. Midwife-led care model for reducing caesarean rate: A novel concept for worldwide birth units where standard obstetric care still dominates. J Med Hypotheses Ideas. 2012;6:28-31.

30. Cheung NF. Chinese midwifery: the history and modernity. Midwifery. 2009; 25:228-41.

31. Ward KN, Byrne JP. A critical review of the impact of continuing breastfeeding education provided to nurses and midwives. J Hum Lact. 2011;27(4):381-93.

32. World Health Organisation. Evidence for the ten steps to successful breastfeeding. Geneva: World Health Organisation; 1998.

33. Bernaix LW. Nurses'attitudes, subjective norms, and behavioral intentions toward support of breastfeeding mothers. J Hum Lac. 2000;16(3):201-9.

34. Dillaway HE, Douma ME. Are pediatric offices supportive of breastfeeding? Discrepancies between mothers' and healthcare professionals' reports. Clin Pediatr (Phila). 2004;43(5):417-30.

35. Hailes J, Wellard S. Support for breastfeeding in the first postpartum month: perceptions of breastfeeding women. Breastfeed Rev. 2000;8(3):5-9.

36. Smale M, Renfrew MJ, Marshall $\lrcorner$, Spiby $H$. Turning policy into practice: more difficult than it seems. The case of breastfeeding education. Matern Child Nutr. 2006;2(2):103-13.

37. Shields N, Turnbull D, Reid M, Smith LN. Satisfaction with midwife managed care in different time periods: a randomised controlled trial of 1299 women. Midwifery. 1998;14:85-93.

38. Villar J, Carroli G, Khan-Neelofur D, Piaggio G, Gülmezoglu M. Patterns of routine antenatal care for low-risk pregnancy. Cochrane Database Syst Rev. 2001;(4):CD000934

39. Cheung NF, Mander R, Wang X, Fu W, Zhou H, Zhang L. Clinical outcomes of the first midwife-led normal birth unit in China: a retrospective cohort study. Midwifery. 2011;27:582-7

40. Parratt J, Fahy K. Including the non rationalis sensible midwifery. Woman Birth. 2008;21:37-42

41. Homer CS, Passant L, Kildea S, Bordie PM. The development of nationa competency standards for the midwife in Australia. Midwifery. 2007;23:350-60.

42. Homer CS, Passant L, Brodie PM, Thorogood C. The role of the midwife in Australia: views of women and midwives. Midwifery. 2009;256:673-81.
43. Hunter B, Berg M, Lundgren I, Olafsdottir OA, Kirkham M. Relationships: the hidden threads in the tapestry of maternity care. Midwifery. 2008:24:132-7.

44. Pembroke N. The spirituality of presence in midwifery. Midwifery. 2008; 24:321-7.

45. Hildingsson I, Radestad I. Swedish women's satisfaction with medical and emotional aspects of antenatal care. J Adv Nurs. 2005:52:239-49.

46. Halldorsdottir S, Karlsdottir S. Empowerment or discouragement: women's experience of caring and uncaring encounters during childbirth. 1996:4:361-79.

47. Gibbins J, Thomson AM. Women's expectations and experiences of childbirth. Midwifery. 2001;17(4):302-13.
Ready to submit your research? Choose BMC and benefit from:

- fast, convenient online submission

- thorough peer review by experienced researchers in your field

- rapid publication on acceptance

- support for research data, including large and complex data types

- gold Open Access which fosters wider collaboration and increased citations

- maximum visibility for your research: over $100 \mathrm{M}$ website views per year

At $\mathrm{BMC}$, research is always in progress.

Learn more biomedcentral.com/submissions 